\title{
OPTIMALISASI MANAJEMEN PENERIMAAN \& PENYIMPANAN DOKUMEN FAX MENGGUNAKAN ALGORITMA GREEDY
}

\author{
Intan Purnamasari ${ }^{1}$, Oman Komarudin ${ }^{2}$ \\ ${ }^{1,2}$ Jurusan Teknik Informatika, Fakultas Ilmu Komputer, Universitas Singaperbangsa Karawang \\ Email: 1intan92@staff.unsika.ac.id, ${ }^{2}$ oman.komarudin@staff.unsika.ac.id
}

(Naskah masuk: 01 Agustus 2018, diterima untuk diterbitkan: 07 November 2019)

\begin{abstract}
Abstrak
Mesin fax pada dasarnya mutlak diperlukan bagi sebuah instansi maupun organisasi tertentu. Namun kesulitan yang dihadapi oleh beberapa perusahaan kecil maupun menengah adalah tidak dapat mengalokasikan dana bagi pembelian mesin fax, perawatan, dan perlengkapan komputer sebagai media penunjang. Bagi perusahaan yang telah memiliki mesin fax pun, manajemen dokumen yang diterima melalui fax menjadi kesulitan tersendiri, dari mulai perawatan mesin fax, pemeriksaan ketersediaan kertas dan cartridge tinta, pemeriksaan dokumen yang diterima, serta penyimpanan arsip fax yang diterima. Metodologi penelitian yang akan digunakan pada penelitian ini adalah metode rakayasa perangkat lunak atau Software Development Life Cyle (SDLC) dengan model pemrograman cepat atau Extreme Programming. Desain pemodelan aplikasi menggunakan UML (Unified Modelling Language) yang diimplementasikan menggunakan bahasa pemrograman PHP sebagai algoritma program dan bahasa pemrograman HTML untuk desain tampilan aplikasi dengan tools aplikasi Notepad++. Hasil implementasi dari aplikasi ini adalah yang semula awalnya penerimaan dokumen fax dengan menggunakan mesin fax harus tercetak dan membutuhkan media kertas sebanyak $100 \%$ mengingat mesin fax hanya dapat menampilkan pesan dan dapat dibaca setelah tercetak namun setelah menggunakan apliksi digifax ternyata dapat menghemat penggunaan kertas sebanyak 24,6\% sehingga penggunaan kertas menurun menjadi 78,6\%. Hal ini karena dengan aplikasi digifax dokumen atau file fax yang diterima dapat disimpan dan dapat dicetak (print) maupun diatur sesuai kebutuhan pengguna.
\end{abstract}

Kata kunci: Dokumen Fax, Penerimaan Dokumen Fax, Algoritma Greedy

\section{OPTIMIZATION OF THE MANAGEMENT OF THE RECEPTION \& STORAGE FAX DOCUMENT USING GREEDY ALGORITHMS}

\begin{abstract}
Fax machine basically is absolutely necessary for a particular institution or organization. However, the difficulties faced by some small and medium enterprises are not able to allocate funds for the purchase of a fax machine, maintenance, and computer equipment as supporting media. For companies that already have a fax machine too, management documents received via fax into its own difficulties, ranging from fax machine maintenance, checking the availability of paper and ink cartridges, examination of documents received, and the received fax archival storage. The research methodology that will be used in research is a method of software engineering or Software Development Life Cyle (SDLC) with fast programming model or Extreme Programming. Design application modeling using UML (Unified Modeling Language) which is implemented using the PHP programming language as the program algorithm and HTML programming language for interface design tool applications with Notepad ++ applications. The results of the implementation of this application is that the original fax document acceptance initially using fax machines need to be printed and paper media as much as 100\% given the fax machine can only display a message and can be read as printed digifax but after using the same practice was able to save the use of paper as much as 24, 6\%, so the use of paper decreased to $78.6 \%$. This is because the application digifax documents or files received faxes can be stored and can be printed (print) and arranged according to user needs.
\end{abstract}

Keywords: Fax machine, Acceptance Fax Document, Greedy Algorithm 


\section{PENDAHULUAN}

Teknologi Informasi (TI) merupakan suatu item yang bermacam-macam dalam kemampuan yang digunakan dalam pembuatan, penyimpanan dan penyebaran data maupun informasi (Senn, 2000). Namun dalam berkomunikasi mapun memperoleh informasi membutuhkan sebuah media komunikasi berupa teknologi informasi yang dapat dimanfaatkan dalam berkomunikasi maupun memperoleh sebuah informasi (Sutarman, 2009). Salah satu teknologi informasi adalah mesin faksmili.

Faksimili adalah teknologi telekomunikasi yang digunakan untuk menyalin dan mengirimkan dokumen yang serupa dengan aslinya, menggunakan jaringan telepon ke mesin fax penerima yang kemudian bisa dicetak dikertas (Internet: 27 April 2013). Seluruh penerimaan pesan yang dikirim melalui fax akan tersimpan dalam folder inbox (kotak masuk). Folder inbox dapat diakses oleh pengguna yang mempunyai akun sebagai akses penerimaan dokumen fax. Namun pada saat folder inbox terisi penuh akan menyebabkan penumpukan dokumen fax dan tidak ada optimasi pilihan apakah dokumen fax akan dipindahkan atau dihapus. Akibatnya pemeriksaan rutin dokumen fax harus dilakukan agar tidak terjadi penumpukan dokumen fax. Hal ini membuat persoalan optimasi yang timbul bagaimana agar dokumen fax tidak menumpuk pada folder inbox. Optimasi atau optimalisasi itu sendiri merupakan metode pemecahan masalah maksimalisasi atau minimalisasi. Menurut Kamus Besar Bahasa Indonesia Optimalisasi berasal dari kata dasar Optimal yang berarti terbaik atau dapat dikatakan sebagai sesuatu yang paling baik dari beberapa pilihan. Optimasi sangat bermanfaat untuk meningkatkan produktivitas kerja (Ambarwari A \& Witdi N, 2016). Salah satu solusi optimasi dapat diatasi menggunakan sebuah algoritma, yaitu algoritma greedy. Algoritma greedy merupakan algoritma yang digunakan untuk pemecahan masalah dalam memilih sebuah solusi optimum dari beberapa elemen kandidat yang dapat digunakan untuk memecahkan masalah yang dimaksud (Munir, 2004). Algoritma ini akan digunakan untuk menentukan solusi terbaik berdasarkan step by step yang digunakan dalam menentukan optimasi sebagai pilihan solusi terbaik (Malik A., Sharma A. \& Saroha V. 2013) terhadap dokumen fax yang akan dipindahkan pada folder tertentu maupun dihapus pada saat folder inbox terisi penuh oleh dokumen fax yang sudah diterima.

Penelitian sebelumnya yang terkait mengenai masalah optimasi dengan algoritma Greedy adalah pencarian rute hotel dengan melakukan penyesuian pengunaan algoritma berdasarkan karakteristik perjalanan yang dilakukan wisatawan (Herly M.A, Raharjana K.I, \& Purbandini, 2015). Kemudian pada penelitian sebelumnya juga, algoritma Greedy dikatakan dapat melakukan klasifikasi, konsistensi, tingkat konvergensi, dan adaptivitas terhadap beberapa persoalan seperti inventory system dan lain sebagainya (Mannor, Meir , \& Zhang, 2003). Selain sebagai optimasi ternyata pada penelitian selanjutnya algoritma greedy dapat digunakan dapat diterapkan dalam pendekteksian aktifitas lansia pada saat berdiri, berjalan, duduk dan berbaring dengan menggunakan alat bantu sensor Arduino Mega. Penelitian tersebut bertujuan untuk menjaga aktivitas lansia agar dapat selalu terkontrol dan dipantau oleh orang disekitarnya (Wahyuningsih, 2018).

Berdasarkan permasalahan yang muncul, penelitian ini bermaksud untuk menggali konsep dan mengimplementasikan penggunaan aplikasi berbasis komputer untuk penerimaan dan manajemen dokumen fax. Selain untuk mendukung langkah go green yang bertujuan untuk mengurangi global warming atas dampak negatif penggunaan kertas yang tidak terpakai, dengan manajemen file melalui aplikasi yang dibangun, dapat dibuat sistematika penyimpanan file berdasarkan tanggal, hak akses, penerusan kepada tujuan yang dimaksud (disposisi), serta akan dibuat suatu optimasi sebagai solusi terbaik yang dilakukan pada saat folder penyimpanan yang terisi penuh dokumen $f a x$.

\section{METODE}

Metodologi penelitian menggunakan System Life Cycle (SDLC) model pengembangan pemrograman cepat (Extreme Programming atau XP) (Pressman, 2010). XP merupakan salah satu pendekatan pengembangan perangkat lunak yang banyak digunakan dalam perangkat lunak cepat dan sedikit lebih rinci (Beck, 2002). XP pada dasarnya menggunakan suatu pendekatan berorientasi objek (Object Oriented) sebagai suatu paradigma pengembangan yang diinginkan yang didalamnya mencakup sebuah aturan dan pratik-pratik yang terjadi dalam konteks empat kegiatan kerangka kerja, yaitu: perencanaan, perancangan, pengkodean, dan pengujian (Pressman, 2010). Tahapan penelitian yang akan dilakukan yaitu : 1) Perencanaan (User Stories), 2) Perancangan, 3) Pengkodean, 4) Pengujian.

\subsection{Perencanaan (User Stories)}

User stories pada penelitian ini merupakan kumpulan cerita awal pengguna yang masuk kedalam klasifikasi pengguna mesin fax mengenai penggunaan dan pemanfaatan mesin fax itu sendiri bagi pengguna. Kemudian pengguna tersebut akan menjadi calon pengguna terhadap sistem yang akan dibuat pada perangkat lunak yang akan dibangun. Hasil dari analisis penggunaan mesin fax ini akan menjadi sebuah kumpulan cerita atau disebut dengan user stories yang dikemukakan oleh pengguna (user) yang dibuat sebuah ringkasan cerita yang dijadikan 
sebagai perencanaan awal bagi penulis dalam membangun aplikasi.

1. Analisis Kebutuhan Fungsional

Analisis ini dilakukan untuk mengetahui secara langsung mengenai kebutuhan pengguna (user) terhadap pemanfaatan mesin fax yang lebih maksimal. Analisis ini bertujuan untuk memudahkan pengembang perangkat lunak dalam membuat fungsionalitas tambahan pada perangkat lunak yang akan dibangun sesuai dengan keperluan penggunanya (user).

2. Analisis Pengguna Sistem

Analisis pengguna sistem ini merupakan analisis pengguna yang didapat berdasarkan klasifikasi pengguna mesin fax yang menjadi calon pengguna sistem yang akan dibuat pada perangkat lunak yang akan dibangun. Analisis ini bertujuan untuk memudahkan pengembang perangkat lunak dalam membangun sistem yang akan dibuat sesuai kebutuhan pengguna (user) pada masalah yang ada saat ini.

\subsection{Perancangan}

Sistem ini dirancang agar mempermudah sebagian orang dalam mengatur penerimaan pesan melalui mesin fax, dan perancangan perangkat lunak yang akan dibangun menggunakan pemodelan Unifed Modeling Language (UML). Adapun perancangan yang akan dipakai dalam sistem ini hanya menggunakan Class Responesibility Collaboration (CRC) dan menggunakan beberapa pemodelan UML, yaitu sebagai berikut:

1. Class Responsibility Collaboration (CRC) Card untuk memperhatikan alur sistem secara keseluruhan dengan pembagian kelas-kelas yang menujukkan kebutuhan-kebutuhan dan tanggung jawab antara kelas yang dibuat sesuai dengan atribut yang digunakan.

2. Use Case yang digunakan sebagai alur aktivitas pengguna (user) terhadap perangkat lunak yang akan dibangun.

3. Activity diagram yang merupakan perluasan dari Use Case yang akan menghasilkan sebuah interaksi antara pengguna dengan perangkat lunak yang kemudian akan penulis terjemahkan menjadi sebuah User Interface atau antar muka pengguna pada perangkat lunak yang akan dibangun.

\subsection{Pengkodean}

Pada tahap ini penulis mengimplementasikan seluruh hasil dari desain arsitektur aplikasi, desain database, dan desain interface yang sebelumnya telah dibuat ke dalam bentuk yang sesungguhnya. Tool atau perangkat lunak yang akan digunakan pada dasarnya adalah DBMS MySQL sebagai implementasi dari desain database, script atau source code bahasa pemrograman PHP yang akan digunakan untuk pembuatan algoritma program dan menggunakan desain tampilan web dengan menggunakan HTML.

Algoritme program akan disertai dengan penggunaan algoritma Greedy (Munir, R. 2004) dalam optimasi solusi terbaik untuk memaksimalkan kapasitas suatu penyimpanan data yang digunakan untuk menyimpan dokumen fax nantinya. Adapun pemaparan skema umum algoritma greedy dalam psedeucode sebagai berikut:

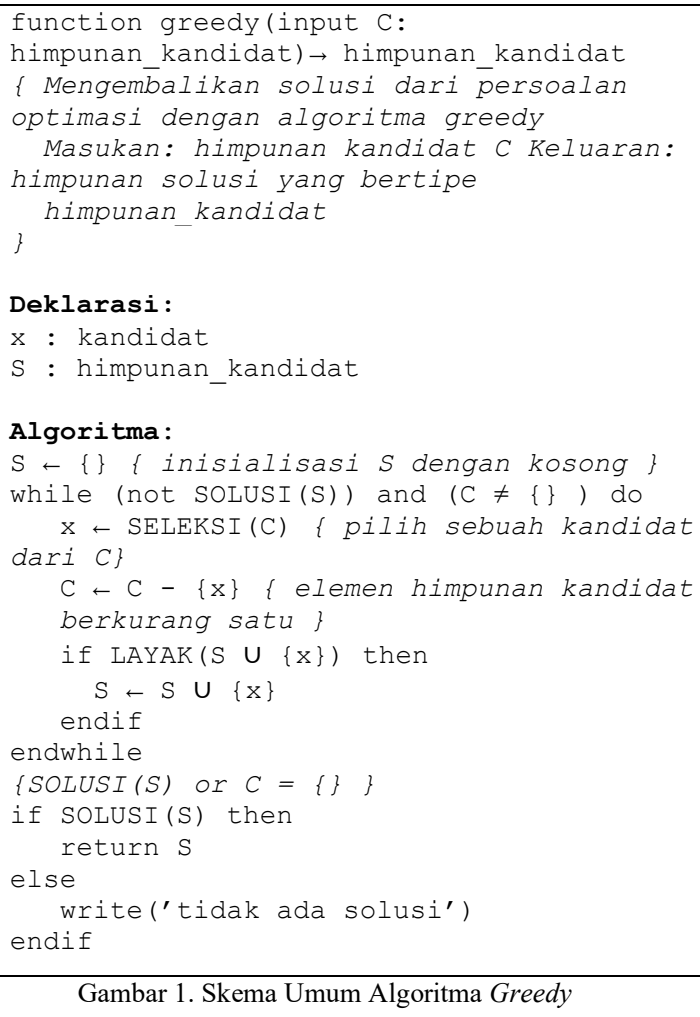

Gambar 1. Skema Umum Algoritma Greedy

\subsection{Pengujian}

Tahap ini dilakukan pada saat keseluruhan tahap sebelumnya telah dilakukan. Tahap pengujian yang akan dilakukan ada dua jenis yaitu dengan menggunakan White Box Testing dan Black Box Testing.

\section{HASIL PENELITIAN}

Berdasarkan dari hasil wawancara dan observasi penulis mendapatkan data terkait dengan penggunaan mesin fax terhadap beberapa organisasi dan instansi tertentu maupun perorangan. 


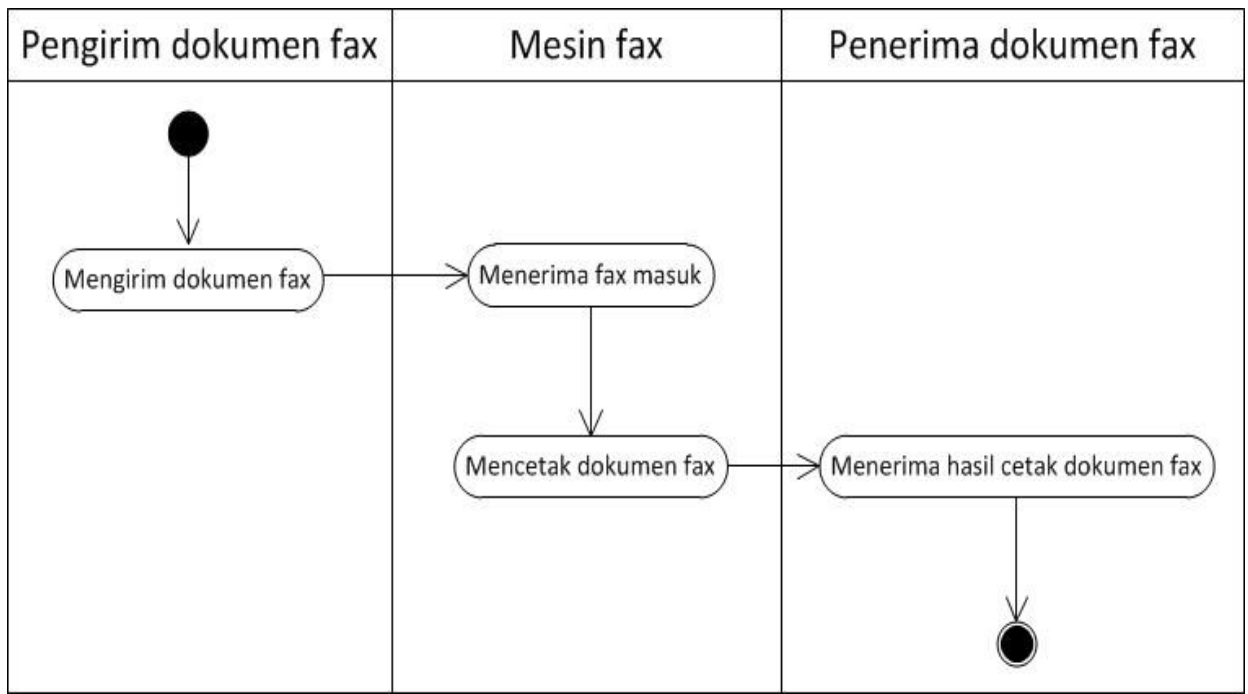

Gambar 2. Activity Diagram Penerimaan Dokumen fax dengan Menggunakan Mesin fax

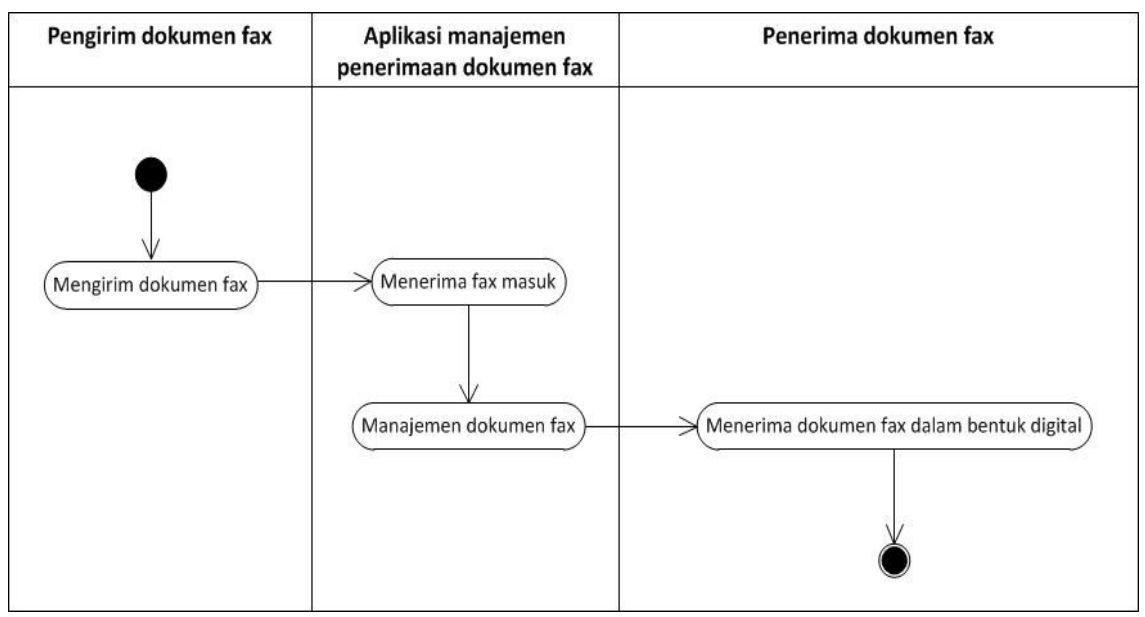

Gambar 3. Activity Diagram Sistem yang Diusulkan

Melihat dari sistem penerimaan dokumen fax kebanyakan pada saat ini, dengan tidak adanya manajemen penerimaan dokumen fax ditambah lagi dokumen fax tersebut tidak tersimpan. Maka diusulkan sistem penerimaan dokumen fax melalui mesin fax dengan manajemen penerimaan dokumen fax dalam bentuk activity diagram pada Gambar 3

Aplikasi yang telah dibangun diberi nama digifax, pembangunan digifax menggunakan tahapan XP ini mengalami hingga lebih dari satu kali iterasi. Iterasi dilakukan pada saat tahapan perancangan dan pengkodean dilakukan demi mendapat hasil yang maksimal.

\subsection{User Stories}

Berdasarkan dari hasil analisis yang telah dilakukan terhadap beberapa pengguna mesin fax menjadi sebuah cerita awal (user stories) dan didapat beberapa pendefinisian masalah sebagai berikut:

1. Dokumen fax yang diterima harus telebih dahulu tercetak agar pesan yang diterima dapat terbaca.
2. Kebanyakan dari pengguna mesin fax kesulitan dalam mencari dokumen fax yang sudah diterima sebelumnya karena dokumen fax yang telah diterima tidak tersimpan.

3. Dokumen fax yang diterima dapat diakses oleh siapa pun sehingga tidak ada keamanan hak akses dapat dikatakan tidak terjamin.

4. Dokumen fax yang diterima tidak selalu merupakan dokumen yang dianggap penting oleh beberapa pengguna mesin fax, sehingga ada banyak beberapa dokumen fax yang terbuang begitu saja.

5. Dokumen fax yang terbuang begitu saja membuat sumber daya seperti kertas dan catridge tinta menjadi terbuang percuma.

Analisis kebutuhan dilakukan untuk mengetahui secara jelas dan tepat terhadap masalah yang ada saat ini yang dihadapi oleh pengguna khususnya bagi pengguna mesin fax.

1. Analisis Kebutuhan Fungsional 
Analisis kebutuhan fungsional dilakukan untuk mengetahui kebutuhan apa saja yang dibutuhkan oleh pengguna (user) itu sendiri terhadap pemanfaatan mesin fax. Dari hasil wawancara dan observasi sesuai dengan user stories yang telah dibuat, maka didapat beberapa kebutuhan pengguna terhadap pemanfaatan mesin fax yaitu:

a. Penerimaan dokumen fax yang terkomputerisasi sehingga dokumen fax yang diterima tidak harus tercetak terlebih dahulu agar pesan didalamnya dapat terbaca. Sehingga hal ini juga dapat menghemat penggunaan kertas dan catridge tinta yang pada umumnya dibutuhkan oleh mesin fax.

b. Manajemen penerimaan dokumen fax yang terurut berdasarkan tanggal penerimaan dokumen fax dan dapat tersimpan, sehingga memudahkan pencarian dokumen fax pada saat dibutuhkan kembali.

c. Penerapan sistem pengelolaan hak akses terhadap pengguna yang berkepentingan saja yang dapat menerima dokumen fax.

2. Analisis Pengguna Sistem

Analisis pengguna sistem dilakukan untuk mencari pengguna yang tepat terhadap aplikasi yang akan dibangun. Hasil analisis ini didapat dari hasil analisis terhadap klasifikasi pengguna mesin fax yang telah dilakukan sebelumnya hanya ada dua pengguna sistem pada aplikasi ini yaitu admin dan user.

\subsection{Perancangan}

Perancangan dilakukan untuk pemetaan atau gambaran desain aplikasi yang akan dibangun. Desain aplikasi yang akan dibangun menggunakan perancangan dengan Class Responesibility Diagram (CRC) Card dan beberapa perancangan dengan pemodelan UML. Dimana desain arsitektur aplikasi dibuat menggunakan CRC Card, use case diagram, activity diagram, dan sequence diagram. Untuk desain database menggunakan class diagram dan untuk representasi dari desain interface menggunakan tools Dia. Berikut perancangan secara garis besar sistem yang telah dibangun.

\subsection{Pengkodean}

Implementasi antarmuka didapat dari desain interface atau tampilan dari aplikasi yang telah dibuat, berikut ini beberapa hasil implementasi dari desain interface atau desain antarmuka yang telah dibuat:

\section{a. Tampilan formLogin}

Berikut merupakan hasil implementasi dari desain login yang telah dibuat pada aplikasi digifax :

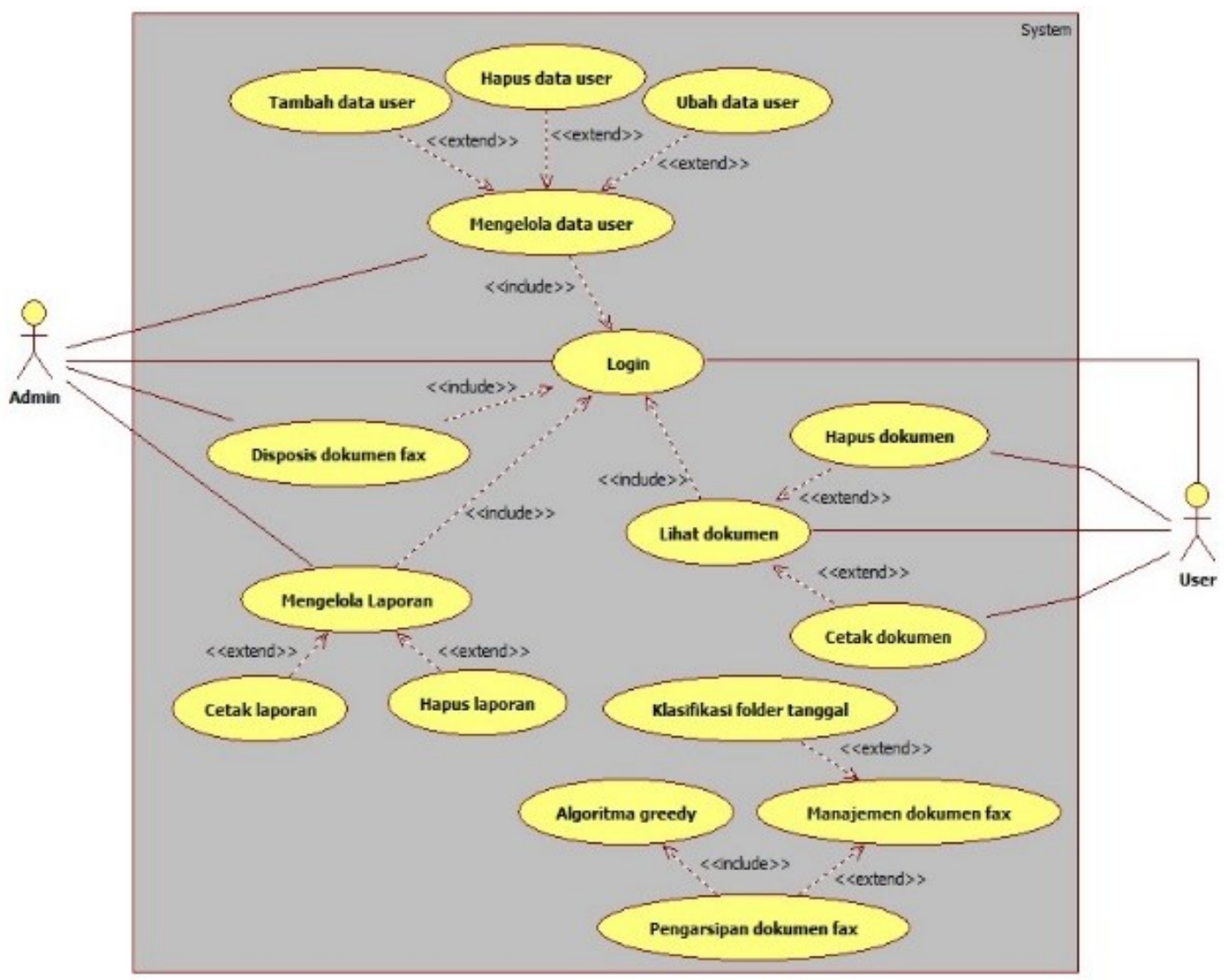

Gambar 4. Use case Diagram Aplikasi Manajemen Penerimaan Dokumen Fax 


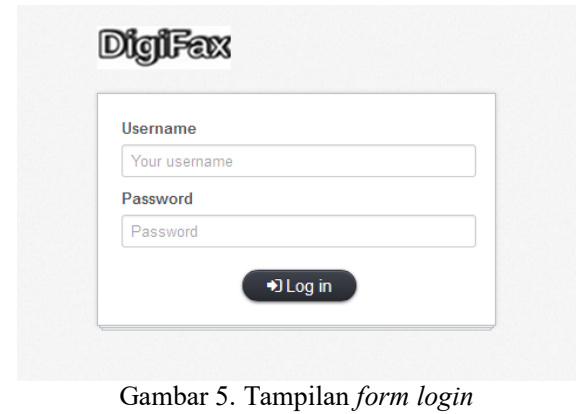

Dari Gambar 5 diatas terdapat dua isian data yaitu username dan password yang akan diisi oleh admin maupun user sesuai dengan username dan password yang dimilikinya jika semua kolom isian teks terisi dengan benar maka tekan tombol bertuliskan login untuk masuk ke menu halaman utama.

b. Tampilan form halaman utama (home) untuk admin

Berikut merupakan hasil implementasi dari desain halaman utama (home) bagi admin yang telah dibuat pada aplikasi digifax.

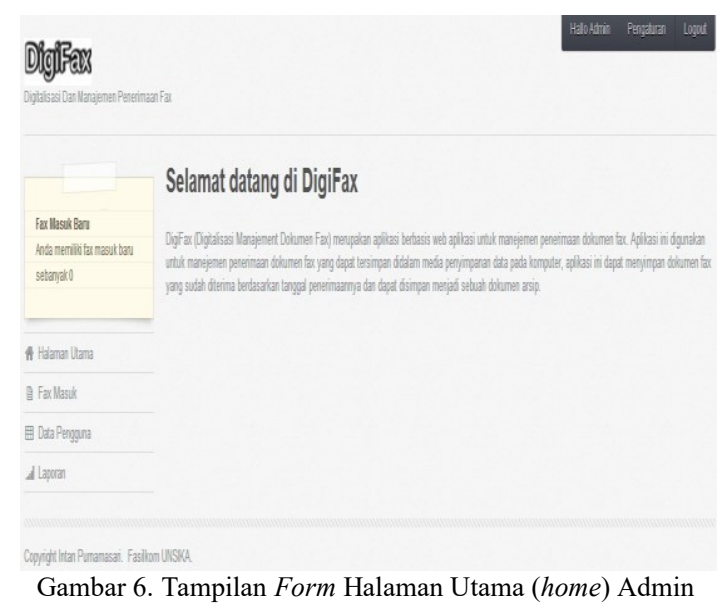

Gambar 6 merupakan tampilan utama bagi admin dari aplikasi digifax dimana terdapat beberapa menu pilihan pada samping kiri halaman yaitu menu Halaman Utama yang sedang ditampilkan disamping kanannya, kemudian ada menu FaxMasuk untuk melihat daftar dokumen fax yang telah diterima, Data Pengguna untuk akses user atau pengguna dan menu Laporan untuk melihat jumlah fax yang masuk.

c. Tampilan form halaman utama (home) untuk user Berikut merupakan hasil implementasi dari desain halaman utama (home) bagi user yang telah dibuat pada aplikasi digifax.

Gambar 7 merupakan tampilan utama bagi user dari aplikasi digifax dimana terdapat beberapa menu pilihan pada samping kiri halaman yaitu menu Halaman Utama yang sedang ditampilkan disamping kanannya dan ada menu FaxMasuk untuk melihat daftar dokumen fax yang telah diterima.

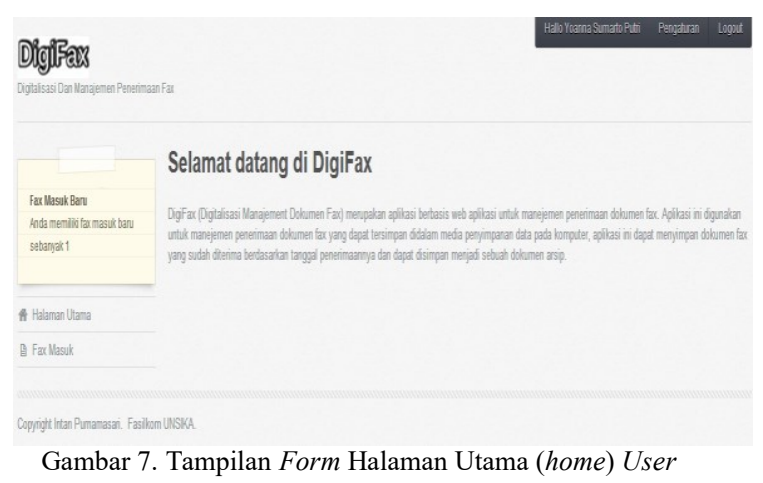

d. Tampilan form lihat data user

Berikut merupakan hasil implementasi dari desain halaman untuk menampilkan data useryang dapat diakses hanya oleh admin yang telah dibuat pada aplikasi digifax.

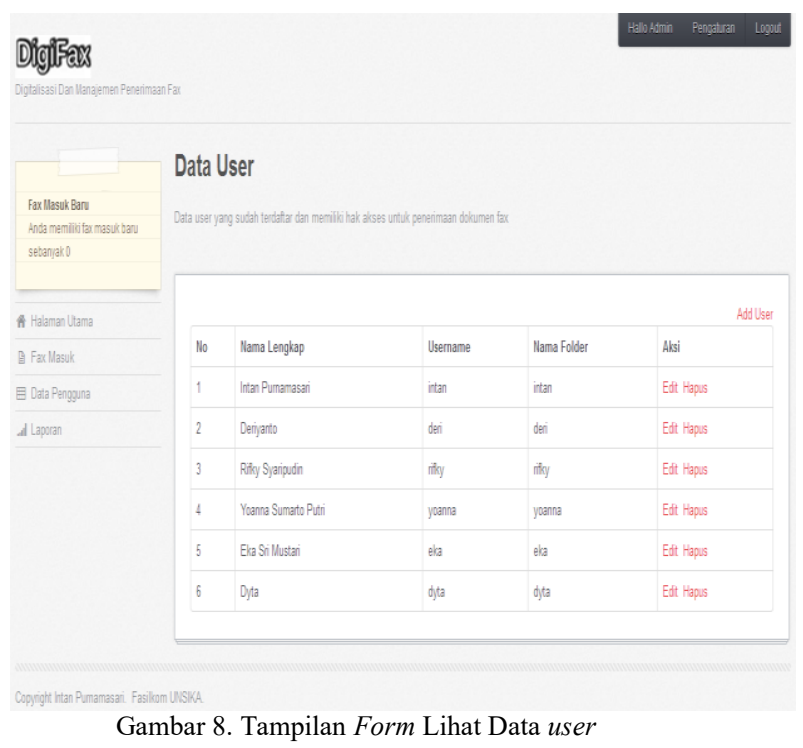

Gambar 8 menampilkan jumlah data user yang tersimpan didalam database yang dapat ditampilkan oleh admin dengan memilih menu Data User untuk membuka daftar data user, admin dapat memilih aksi Edit dan Hapus untuk memperbaharui data user yang sebelumnya sudah ditambahkan, selain itu admin dapat menambahkan data user yang baru dengan mengklik Add User agar tampil sebuah tampilan atau form untuk menambah data baru.

e. Tampilan form tambah data user

Berikut merupakan hasil implementasi dari desain halaman untuk menambah data useryang dapat diakses hanya oleh admin yang telah dibuat pada aplikasi digifax : 


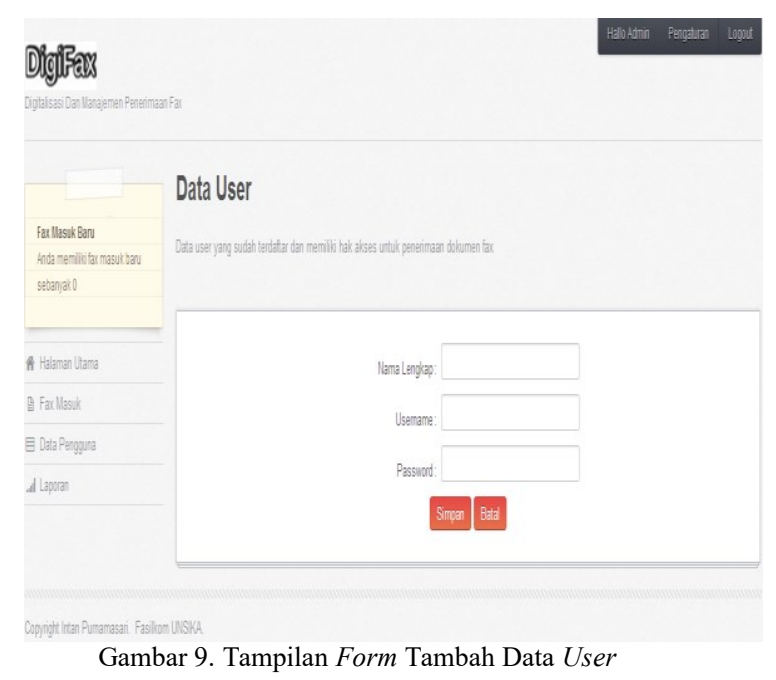

Gambar 9 merupakan tampilan atau form untuk menambah data user baru jika semua kolom isian terisi dengan lengkap maka jika admin menekan tombol Simpan data yang sudah dimasukkan akan tersimpan ke dalam database, sebaliknya jika admin menekan tombol Batal maka akan kembali ke menu sebelumnya.

f. Tampilan form edit atau ubah data user Berikut merupakan hasil implementasi dari desain halaman untuk mengubah data useryang dapat diakses hanya oleh admin yang telah dibuat pada aplikasi digifax :

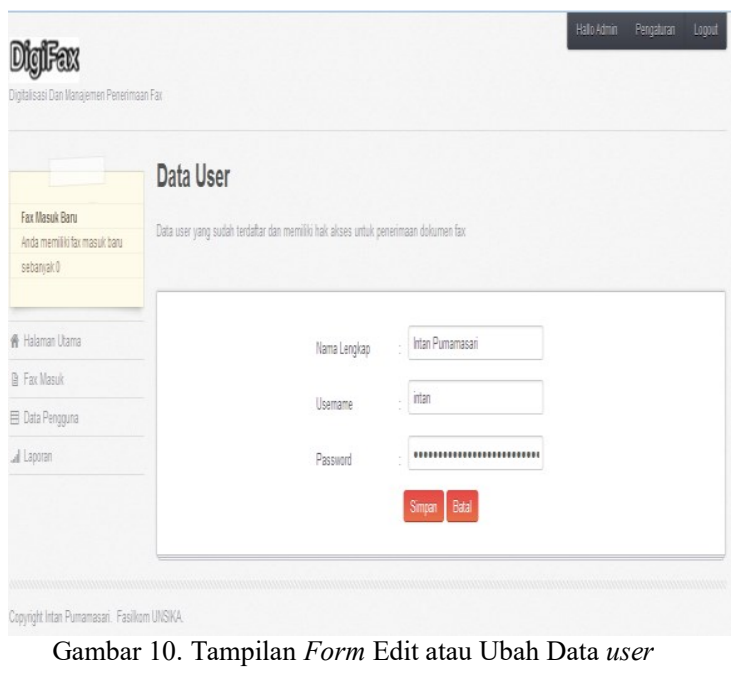

Gambar 10 merupakan tampilan atau form untuk mengubah data user baru jika semua kolom isian terisi dengan lengkap maka jika admin menekan tombol Simpan data yang sudah dimasukkan atau sudah selesai diubah akan tersimpan ke dalam database, sebaliknya jika admin menekan tombol Batal maka akan kembali ke menu sebelumnya.

g. Tampilan form disposisi dokumen fax Berikut merupakan hasil implementasi dari desain halaman untuk disposisi dokumen fax yang dilakukan oleh admin untuk hak akses dokumen fax terhadap user yang telah dibuat pada aplikasi digifax :

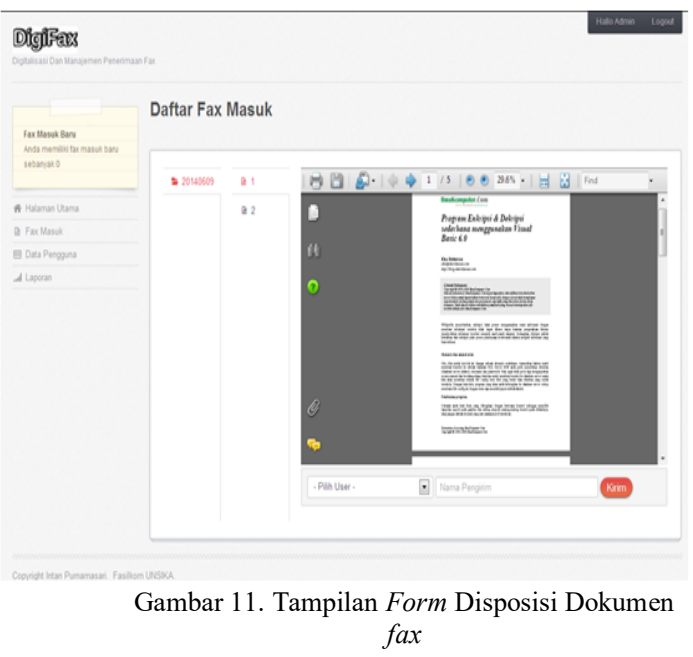

Gambar 11 merupakan tampilan atau form untuk disposisi dokumen fax kepada user sesuai dengan hak akses dokumen fax yang sudah diterima. Jika dokumen fax ditujukan untuk satu user admin memilih bagian list data user yang dimaksud kemudian mencantumkan nama pengirim lalu menekan tombil Kirim, maka dokumen fax yang sudah terkirim tersebut akan tersimpan ke dalam folder simpan user yang telah ditujukan.

h. Tampilan form laporan penerimaan dokumen $f a x$ Berikut merupakan hasil implementasi dari desain halaman laporan penerimaan dokumen fax yang telah dibuat pada aplikasi digifax:

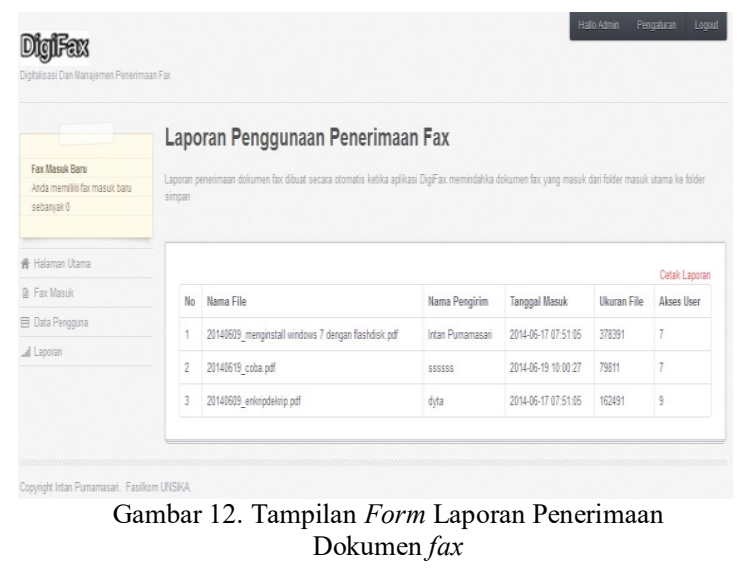

Gambar 12 merupakan tampilan atau form untuk menampilkan laporan penerimaan dokumen fax yang sudah tersimpan didalam database, form ini hanya dapat diakses oleh admin dan apabila admin memilih aksi CetakLaporan maka laporan penerimaan dokumen fax akan tercetak dalam bentuk hardcopy. 


\subsection{Pengujian}

Pengujian dilakukan dengan dua metode yaitu menggunakan Black BoxTesting dan White Box Testing. Black Box Testing dilakukan untuk menguji fungsi-fungsi yang terdapat pada aplikasi apakah sudah sesuai atau belum sehingga dapat dikatakan user friendly. Sedangkan White Box Testing digunakan untuk pengujian terhadap logika program yang dibuat pada aplikasi digifax.

1. Pengujian menggunakan Whitebox

Pengujian whitebox dilakukan untuk menguji logika program dengan algoritma program terhadap aplikasi yang telah dibuat. Pengujian whitebox untuk klasifikasi folder berdasarkan tanggal terbagi atas dua opsi yaitu admin dan user, sebelum admin dan user memiliki folder berdasarkan tanggal sesuai dengan tanggal dokumen fax yang masuk, maka admin dan user harus terlebih dahulu memiliki folder simpan sebagai folder utama untuk menyimpan folderfolder baru beserta isi file dokumen fax-nya sesuai tanggal penerimaan dokumen fax. Berikut ini merupakan pengujian whitebox cek validasi untuk membuat folder simpan berdasarkan dua opsi yaitu bagi admin dan user.

\begin{tabular}{|c|c|}
\hline 1 & $\begin{array}{l}<\text { ?php } \\
\text { session_start(); } \\
\text { include_once('koneksi.php'); } \\
\text { date_default_timezone_set } \\
\text { ("Asia/Jakarta"); } \\
\text { \$tgl = date('Ymd'); }\end{array}$ \\
\hline 2 & 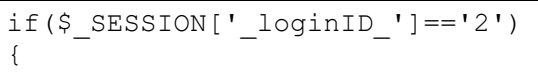 \\
\hline 3 & $\begin{array}{l}\text { \$folderMasuk = } \\
\quad \text { option('folder_masuk'); } \\
\text { \$folderSimpan = } \\
\quad \text { option('folder_simpan'); } \\
\text { include 'greedy.php'; }\end{array}$ \\
\hline 4 & \} else \{ \\
\hline 5 & $\begin{array}{l}\text { \$folderMasuk=option('folder_fax' } \\
\text { )."/". } \\
\text { \$_SESSION ['_loginID_']; } \\
\text { \$folderSimpan=\$folderMasuk; }\end{array}$ \\
\hline 6 & \} \\
\hline
\end{tabular}

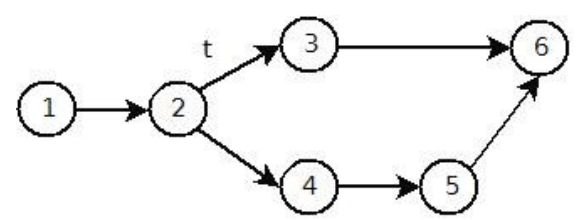

Gambar 13. Pengujian Whitebox untuk Validasi Membuat Folder Simpan bagi Admin atau User

$$
\begin{aligned}
\mathrm{V}(\mathrm{G}) & =\mathrm{E}-\mathrm{N}+2 \\
& =6-6+2 \\
& =2
\end{aligned}
$$

$$
\begin{aligned}
\mathrm{V}(\mathrm{G}) & =\mathrm{P}+1 \\
& =1+1 \\
& =2
\end{aligned}
$$

Jadi, dapat disimpulkan dari pengujian whitebox pada pengujian diatas terdapat 2 alur path untuk membuat foldersimpan sebagai penyimpanan dokumen fax yang telah diterima, yaitu sebagai berikut:

1. Path $1=1-2-3-6$

2. Path $2=1-2-4-5-6$

Selanjutnya setelah pengujian diatas dilakukan maka langkah selanjutnya adalah mengecek apakah folder yang baru dibuat sudah ada sebelumnya atau belum. Makadilakukan pengujian whitebox cek validasi untuk mengecek apakah folder yang akan dibuat sudah ada atau belum sebelumnya seperti gambar 14 .

\begin{tabular}{ll}
\hline & $\begin{array}{l}<\text { php } \\
\text { \$folderFax=\$folderSimpan. "/".\$tg } \\
1 ;\end{array}$ \\
\hline 2 & if(!file_exists (\$folderSimpan \\
\hline 3 & \{ \\
\hline & mkdir(\$folderSimpan); \\
4 & ?> \\
\hline
\end{tabular}

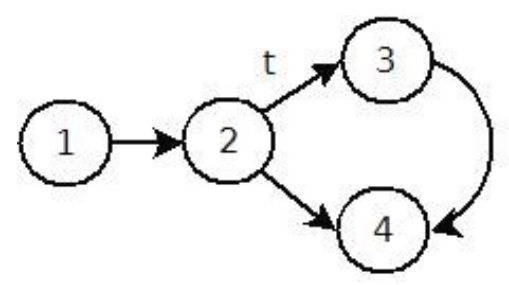

Gambar 14. Pengujian Whitebox Validasi untuk Membuat Folder Simpan

$$
\begin{array}{rlrl}
\mathrm{V}(\mathrm{G}) & =\mathrm{E}-\mathrm{N}+2 & \mathrm{~V}(\mathrm{G}) & =\mathrm{P}+1 \\
& =4-4+2 & & =1+1 \\
& =2 & & =2
\end{array}
$$

Jadi, dapat disimpulkan dari pengujian whitebox pada pengujiandiatasterdapat 2 alur path untuk mengecek apakah folder yang akan dibuat sudah ada atau belum sebelumnya sebagai penyimpanan dokumen fax yang telah diterima, yaitu sebagai berikut:

1. Path $1=1-2-3-4$

2. Path $2=1-2-4$

Langkah selanjutnya setelah folder simpan untuk admin dan user telah dibuat maka folder masuk yang merupakan folder utama untuk menyimpan dokumen fax yang diterima pertama kali dicek oleh admin sehingga dokumen atau file fax yang telah diterima tersimpan pada folder simpan milik admin, kemudian usermendapat dokumen atau file fax yang diterima dengan menunggu konfirmasi dari admin . Berikut pengujian whitebox untuk memindahkan dokumen atau file fax dari folder masuk ke folder simpan milik admin maupun user. 


\begin{tabular}{|c|c|}
\hline 1 & $\begin{array}{l}<\text { ?php } \\
\text { \$bukaFolderMasuk = } \\
\quad \text { opendir (\$folderMasuk) ; }\end{array}$ \\
\hline 2 & if (\$bukaFolderMasuk) \\
\hline 3 & \{ \\
\hline 4 & $\begin{array}{l}\text { while(FALSE } !=(\text { \$fileMasuk }= \\
\text { readdir (\$bukaFolderMasuk)) }\end{array}$ \\
\hline 5 & \{ \\
\hline 6 & 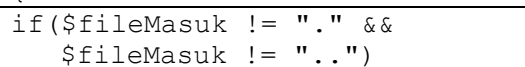 \\
\hline & \{ \\
\hline 7 & $\begin{array}{l}\text { \$tglfile }= \\
\text { filectime (\$folderMasuk."/".\$ } \\
\text { fileMasuk); \$tgll= } \\
\text { date('Ymd', \$tgl file); }\end{array}$ \\
\hline 8 & if (\$SESSION [' $\left.\left.\operatorname{loginID}{ }^{\prime}\right]==2^{\prime}\right)$ \\
\hline 9 & $\begin{array}{l}\text { \{rename (\$folderMasuk."/". \$fileMa } \\
\quad \text { suk, } \\
\quad \text { \$folderMasuk."/".\$tgl1."_".\$ } \\
\quad \text { fileMasuk); } \\
\text { \$namaBaru = } \\
\quad \text { \$tgll."_".\$fileMasuk; } \\
\text { \$folderFax = } \\
\quad \text { \$folderSimpan."/".\$tgl1; }\end{array}$ \\
\hline 10 & if(!file exists (\$folderFax)) \\
\hline 11 & $\begin{array}{l}\{ \\
\operatorname{mkdir}(\$ f \circ l d e r F a x)\end{array}$ \\
\hline 12 & $\begin{array}{l}\text { \$fileAsal = } \\
\text { \$folderMasuk."/". \$namaBaru; } \\
\text { \$fileTujuan = } \\
\quad \text { \$folderFax."/".\$namaBaru; } \\
\text { copy(\$fileAsal, \$fileTujuan); } \\
\text { unlink(\$fileAsal); }\end{array}$ \\
\hline 13 & \}else \{ \\
\hline 14 & $\begin{array}{l}\text { \$namaBaru }=\text { \$fileMasuk; } \\
\}\end{array}$ \\
\hline 15 & \} \\
\hline 16 & \} \\
\hline 17 & $\begin{array}{l}3 \\
?>\end{array}$ \\
\hline
\end{tabular}

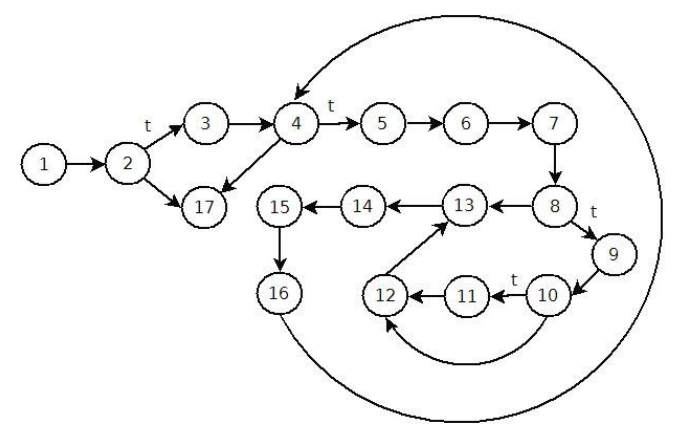

Gambar 15. Pengujian Whitebox Memindakan Dokumen fax dari Folder Utama ke Folder Simpan

$$
\begin{aligned}
\mathrm{V}(\mathrm{G}) & =\mathrm{E}-\mathrm{N}+2 \\
& =20-17+2 \\
& =5
\end{aligned}
$$$$
\begin{aligned}
\mathrm{V}(\mathrm{G}) & =\mathrm{P}+1 \\
& =4+1 \\
& =5
\end{aligned}
$$

Jadi, dapat disimpulkan dari pengujian whitebox pada pengujiandiatasterdapat 5 alur path untuk memindahkan dokumen atau filefax dari folder masuk ke folder simpan milik admin yaitu sebagai berikut:

1. Path $1=1-2-3-4-5-6-7-8-9-10$ $-11-12-13-14-15-16-4-17$

2. Path $2=1-2-3-4-5-6-7-8-13-14$ $-15-16-4-17$
3. Path $3=1-2-3-4-5-6-7-8-13-14$ $-15-16$

4. Path $4=1-2-3-4-17$

5. Path $5=1-2-17$

2. Pengujian menggunakan Blackbox Pengujian blackbox dilakukan untuk menguji data masukkan maupun keluaran terhadap respon sistem yang dilakukan.

a. Pengujian blackbox login

\begin{tabular}{|c|c|c|c|}
\hline $\begin{array}{c}\text { Data } \\
\text { Masukkan }\end{array}$ & Harapan & $\begin{array}{c}\begin{array}{c}\text { Respon } \\
\text { sistem }\end{array} \\
\end{array}$ & Hasil \\
\hline $\begin{array}{l}\text { Username } \\
\text { dan } \\
\text { Password } \\
\text { valid atau } \\
\text { benar. }\end{array}$ & $\begin{array}{l}\text { Tampil } \\
\text { halaman } \\
\text { utama } \\
\text { (home) }\end{array}$ & $\begin{array}{l}\text { Tampil } \\
\text { halaman } \\
\text { utama } \\
\text { (home) }\end{array}$ & Diterima \\
\hline $\begin{array}{l}\text { Username } \\
\text { dan } \\
\text { Password } \\
\text { kosong. }\end{array}$ & $\begin{array}{l}\text { Tampil pesan } \\
\text { "Password } \\
\text { belum diisi" }\end{array}$ & $\begin{array}{l}\text { Tampil } \\
\text { pesan } \\
\text { "Password } \\
\text { belum diisi" }\end{array}$ & Diterima \\
\hline $\begin{array}{l}\text { Username } \\
\text { diisi dan } \\
\text { Password } \\
\text { kosong. }\end{array}$ & $\begin{array}{l}\text { Tampil pesan } \\
\text { "Username } \\
\text { belum diisi" }\end{array}$ & $\begin{array}{l}\text { Tampil } \\
\text { pesan } \\
\text { "Username } \\
\text { belum diisi" }\end{array}$ & Diterima \\
\hline $\begin{array}{l}\text { Username } \\
\text { kosong dan } \\
\text { Password } \\
\text { diisi. }\end{array}$ & $\begin{array}{l}\text { Tampil pesan } \\
\text { "Username } \\
\text { dan } \\
\text { Password } \\
\text { belum } \\
\text { diisi" }\end{array}$ & $\begin{array}{l}\text { Tampil } \\
\text { pesan } \\
\text { "Username } \\
\text { dan } \\
\text { Password } \\
\text { belum } \\
\text { diisi" } \\
\end{array}$ & Diterima \\
\hline $\begin{array}{l}\text { Username } \\
\text { dan } \\
\text { Password } \\
\text { tidak valid } \\
\text { atau salah. }\end{array}$ & $\begin{array}{l}\text { Tidak masuk } \\
\text { ke halaman } \\
\text { utama dan } \\
\text { Tampil pesan } \\
\text { "Username } \\
\text { tidak } \\
\text { ditemukan!" }\end{array}$ & $\begin{array}{l}\text { Tidak masuk } \\
\text { ke halaman } \\
\text { utama dan } \\
\text { Tampil } \\
\text { pesan } \\
\text { "Username } \\
\text { tidak } \\
\text { ditemukan } \\
\text { !"' }\end{array}$ & Diterima \\
\hline
\end{tabular}

Berikut merupak tabel penjelasan blackbox untuk form login yang telah dibuat:

b. Pengujian blackbox tambah data user Berikut merupak tabel penjelasan blackbox untuk form login yang telah dibuat:

\begin{tabular}{llll}
\multicolumn{4}{c}{ Tabel 2. Pengujian Blackbox Tambah Data User } \\
\hline $\begin{array}{c}\text { Data } \\
\text { Masukkan }\end{array}$ & Harapan & $\begin{array}{c}\text { Respon } \\
\text { sistem }\end{array}$ & Hasil \\
\hline Semua isian & $\begin{array}{l}\text { Data } \text { user } \\
\text { tersimpan }\end{array}$ & $\begin{array}{l}\text { Data } \text { user } \\
\text { tersimpan }\end{array}$ & Diterima \\
diisi dengan & dalam & dalam & \\
database, & database, & \\
& dan tampil & dampil & \\
& pesan data & pesan data & \\
& berhasil & berhasil & \\
& disimpan. & disimpan. & \\
\hline Semua isian & Data user & Data & \\
tidak terisi & tidak & usertidak & Diterima \\
dengan benar & tersimpan & tersimpan & \\
& dalam & dalam & \\
& database, & database, & \\
& dan tampil & dan tampil & \\
& pesan data & pesan data & \\
& gagal & gagal & \\
& disimpan. & disimpan.” & \\
& & &
\end{tabular}

c. Pengujian blackbox disposisi dokumen fax Berikut merupak tabel penjelasan blackboxuntuk disposisi dokumen fax yang 
dilakukan oleh admin dengan mengirimkan dokumen fax ke folderuser:

\begin{tabular}{|c|c|c|c|}
\hline $\begin{array}{c}\text { Data } \\
\text { Masukkan }\end{array}$ & Harapan & $\begin{array}{c}\text { Respon } \\
\text { sistem }\end{array}$ & Hasil \\
\hline $\begin{array}{l}\text { Mengirim } \\
\text { dokumen fax } \\
\text { pada data user } \\
\text { yang benar } \\
\text { dengan } \\
\text { menekan } \\
\text { tombol } \\
\text { "Kirim" }\end{array}$ & $\begin{array}{l}\text { Dokumen } \\
\text { fax } \\
\text { tersimpan } \\
\text { pada folder } \\
\text { user dan } \\
\text { tampil } \\
\text { pesan fax } \\
\text { berhasil } \\
\text { dikirim. }\end{array}$ & $\begin{array}{l}\text { Dokum } \\
\text { en } f a x \\
\text { tersimp } \\
\text { an pada } \\
\text { folder } \\
\text { user } \\
\text { dan } \\
\text { tampil } \\
\text { pesan } \\
\text { fax } \\
\text { berhasil } \\
\text { dikirim. }\end{array}$ & Diterima \\
\hline $\begin{array}{l}\text { Tidak } \\
\text { mengirim } \\
\text { dokumen fax } \\
\text { pada user dan } \\
\text { tidak menekan } \\
\text { tombol } \\
\text { "Kirim" }\end{array}$ & $\begin{array}{l}\text { Dokumen } \\
\text { fax tidak } \\
\text { tersimpan } \\
\text { pada } \\
\text { folderuser } \\
\text { dan tidak } \\
\text { akan tampil } \\
\text { pesan fax } \\
\text { berhasil } \\
\text { dikirim. }\end{array}$ & $\begin{array}{l}\text { Dokum } \\
\text { en } f a x \\
\text { tidak } \\
\text { tersimp } \\
\text { an pada } \\
\text { folderus } \\
\text { er dan } \\
\text { tidak } \\
\text { akan } \\
\text { tampil } \\
\text { pesan } \\
\text { fax } \\
\text { berhasil } \\
\text { dikirim. }\end{array}$ & Diterima \\
\hline
\end{tabular}

\section{EVALUASI SISTEM}

Hasil wawancara dan implementasi aplikasi selama satu bulan penerimaan dokumen fax yang harus tercetak berkurang setelah menggunakan aplikasi digifax. Berdasarkan data yang didapat user atau pengguna harus mencetak keseluruhan dokumen fax yang diterima berapa pun jumlahnya, namun setelah menerapkan aplikasi digifax dokumen fax yang diterima tidak harus dicetak secara keseluruhan. Sehingga penggunaan kertas untuk menerima dokumen faxberkurang karena dokumen fax yang dianggap penting saja yang dicetak oleh pengguna, seperti dokumen yang harus ditandatangani atau merupakan dokumen penting yang harus dikirim dalam bentuk hardcopy.

\begin{tabular}{ccccc} 
Tabel 4. Hasil Implementasi Penggunaan Aplikasi Digifax \\
\hline $\begin{array}{c}\text { Minggu } \\
\text { Ke }-\end{array}$ & \multicolumn{2}{c}{ Sebelum } & \multicolumn{2}{c}{ Sesudah } \\
\cline { 2 - 5 } & Jumlah & Persentase & Jumlah & Persentase \\
\hline 1 & 8 & $100 \%$ & 3 & $37,5 \%$ \\
2 & 12 & $100 \%$ & 2 & $16,6 \%$ \\
3 & 7 & $100 \%$ & 1 & $14,2 \%$ \\
4 & 10 & $100 \%$ & 2 & $20 \%$ \\
\hline
\end{tabular}

Dari data tabel diatas terlihat pada setiap minggu selama satu bulan penggunaan kertas dalam penerimaan dokumen fax dengan menggunakan mesin fax sebanyak 100\%. Setelah menggunakan aplikasi digifax penggunaan kertas berkurang perminggunya, meski seharusnya setelah penggunaan aplikasi digifax sebanyak $0 \%$ namun pada kenyataannya ada beberapa memang dokumen fax yang harus dicetak (print) seperti dokumen yang harus ditandatangani maupun dokumen yang harus dikirim dalam bentuk hardcopy.

Dalam hal ini penulis melakukan perhitungan uji normalitas terlebih dahulu untuk menguji data yang didapat sebelum dan sesudah penggunaan kertas dengan uji klomogorov smirnov dengan taraf signifikan 0,05 atau $\alpha=5 \%$ menggunakan aplikasi IBM SPSS Statistic Versi 21 didapat distribusi normal sebagai berikut:

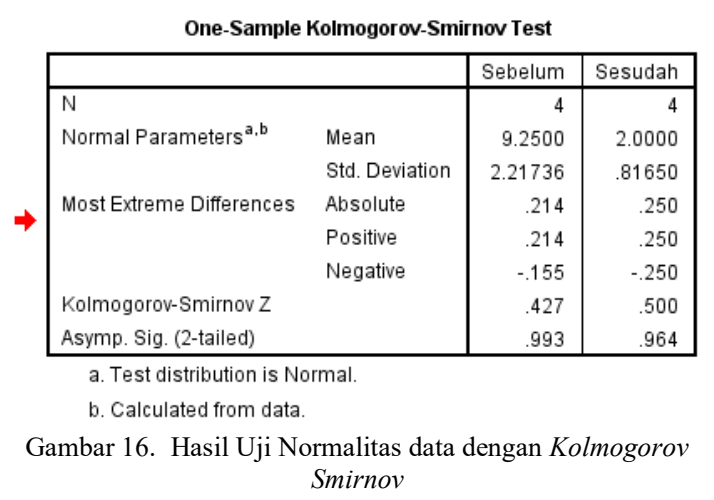

\section{KESIMPULAN}

Berdasarkan tahap-tahap penelitian yang telah dilakukan aplikasi Digifax dapat menghemat penggunaan kertas, yang semula membutuhkan media kertas dan tinta untuk mencetak dokumen atau file fax yang diterima sebanyak $100 \%$ perminggunya namun setelah menggunakan aplikasi digifax dapat menghemat kertas sebanyak $37,5 \%$ pada minggu pertama, $16,6 \%$ pada minggu kedua, $14,2 \%$ pada minggu ketiga dan $20 \%$ pada minggu keempat. Hal ini karena dengan aplikasi digifax dokumen atau file fax yang diterima dapat disimpan dan dapat dicetak (print) sesuai kebutuhan pengguna.

Selain itu aplikasi digifax dapat menyimpan dokumen atau file fax yang sudah diterima dalam bentuk digital sebagai arsip atau dokumen penting bagi pengguna. Hal penting lainnya yaitu aplikasi digifax mempunyai sistem optimasi sebagai pilihan solusi yang tepat bagi pengguna, jika suatu saat tempat penyimpanan dokumen fax penuh maka dokumen fax dapat disimpan dalam folder arsip. Kemudian selain itu aplikasi digifax dapat mengelola dan memberikan hak akses terhadap arsip dokumen fax hanya untuk yang berkepentingan berdasarkan user previlige yang dapat dilakukan oleh seorang admin.

\section{DAFTAR PUSTAKA}

SIMARMATA, J., 2000. Pengenalan Teknologi Komputer dan Informasi, Yogyakarta: Andi.

SUTARMAN, S. M., 2009. Pengantar Teknologi Informasi, Jakarta: Bumi Aksara.

INTERNET., $<$ http://www.engineeringtown.com/kids/ind ex.php/penemuan/172-sejarahditemukannya mesin-fax.Sabtu> [Diakses 27 April 2013] 
KAMUS BESAR BAHASA INDONESIA, 1994. Jakarta . Balai Pustaka. hlm. 800

MUNIR RENALDY, M., 2004. Algoritma Greedy. Bandung. Informatika.

MALIK A., SHARMAA., \& SAROHA V., 2013. Greedy Algorithm. International Journal of Scientific and Research Publications, ISSN: 250-3153, vol.3, no.8, 1-5.

BECK K., 2002. Extreme Programming Explained: Embarce Change Ed.2. Wesley: Addison.

PRESSMAN R. S., 2010. Rekayasa Perangkat Lunak terjemahan dari "Software Engineering" Ed.7. Yogyakarta: Andi.

AMBARWARI A, YANTO W.N., 2016. Penerapan Algoritma Greedy pada Permas alahan Knapsack untuk Optimasi Pengangk utan Peti Kemas. Tersedia melalui : Research Gate

$<$ https://www.researchgate.net/publication/ 290797775_Penerapan_Algoritma_Greedy Pada_Permasalahan_Knapsack_Untuk_O ptimasi_Pengangkutan_Peti_Kemas> [Diakses 30 Juli 2018]

HERLY M.A, RAHARJANA K.I, \& PURBANDINI., 2015. Sistem Pencarian Hotel Berdasarkan Rute Perjalanan Terpendek dengan Mempertimbangkan Daya Tarik Wisata Menggunakan Algoritma Greedy. Journal of Information Systems Engineering and Business Intelligence. EISSN: 2443-2555, vol.1, no.1, 9-15.

MANOR S., MEIR S., \& ZHANG T., 2003. Greedy Algorithms for Classification-Consistency, Convergence-Rates, and Adaptivity. Journal of Machine Learning Research 4. 713-742.

WAHYUNINGSIH P., 2018. Sistem Pencarian Hotel Berdasarkan Rute Perjalanan Terpendek dengan Mempertimbangkan Daya Tarik Wisata Menggunakan Algoritma Greedy. Journal of Information Systems En Penerapan Algoritma Greedy Untuk Mendeteksi Aktivitas Lansia Pada Karpet Menggunakan Arduino Mega. Jurnal INSTEK (Informatika Sains dan Teknologi). ISSN: 2541-1179, E-ISSN : 2581-1711, vol.3, no.1, 51-60. 
Halaman ini sengaja dikosongkan 